\title{
Método de cálculo de MCL entre TVD e LTE
}

\author{
Marcus Aurélio Ribeiro Manhães e Marcos Baracho Trindade (Fundação CPqD)
}

\begin{abstract}
This article displays a methodology for calculating a Minimum Coupling Loss (MCL) to estimate the minimum distance between DTV receivers and LTE transmitters that must share spectral adjacency. The release of the $700 \mathrm{MHz}$ frequency range, considered the digital dividend, implies the necessary interaction between the DTV and the LTE systems. The method estimates the number of mitigation filters to be installed with to $\mathrm{TV}$ receivers in the vicinity of a base station. However, it can also be used to analyze the coexistence of LTE with analog TV, since the related parameters are considered.
\end{abstract}

Index Terms - $700 \mathrm{MHz}$, Convivência TVD/LTE, Dividendo Digital, MCL, Mitigação.

\section{INTRODUÇÃO}

$\mathrm{E}$ ste trabalho contribui para a análise da convivência entre o Sistema de Televisão e o Serviço Móvel Pessoal (SMP) em $700 \mathrm{MHz}$, ao propor um método de cálculo de Minimum Coupling Loss (MCL), para quantificar o afastamento mínimo entre a antena residencial de TV e a torre de transmissão SMP.

Por meio da Portaria No 481 de julho de 2014 do Ministério das Comunicações [1], foi definido o cronograma de desligamento da TV Analógica, efetivando a transição desta faixa de espectro até novembro de 2018.

A convivência entre os sistemas de TV, digital e analógico, está consolidada e sustentada em normas técnicas. Porém, até findar o desligamento (switch off) das transmissões analógicas e consequente realocação espectral de canais de TV acima de 698 $\mathrm{MHz}$, ocorrerão situações nas quais os sistemas de TV estarão se sobrepondo em uma mesma parte do espectro eletromagnético, ora reatribuída para o SMP. Consolidar a convivência da TV com o SMP ainda exige aplicação teórica e prática com o propósito de dirimir todas as questões.

Com a Resolução $n^{\circ}$ 640, de 11 de julho de 2014 [2], foi aprovado o Regulamento sobre as condições de convivência entre os serviços de radiodifusão de sons e imagens e de retransmissão de televisão do Sistema Brasileiro de Televisão Digital (SBTVD) e os serviços de radiocomunicação operando na faixa de $698 \mathrm{MHz}$ a $806 \mathrm{MHz}$, que é referenciada também

como a faixa de $700 \mathrm{MHz}$. Este regulamento oferece informações para a mitigação das possíveis interferências, mas

Artigo submetido à avaliação de publicação em 19/06/2015. Este trabalho foi desenvolvido durante o processo de suporte e consultoria realizado pela Fundação $\mathrm{CPqD}$ à Entidade Administradora de Processo de Redistribuição do não traz considerações diretas para o período de transição, sem abordar o sistema de TV analógica.

No Brasil inúmeros testes foram desenvolvidos com o intuito de determinar a relação de proteção e limiar de bloqueio nos sistemas em convivência. Conforme relatório de testes em campo da Anatel [3], podem ser destacados:

- Testes realizados pela Anatel no Centro de Comunicações e Guerra Eletrônica do Exército;

- Determinação da Relação de Proteção realizada pelo Laboratório de Pesquisas em TV Digital da Escola de Engenharia da Universidade Presbiteriana Mackenzie;

- Considerações da Sociedade Brasileira de Engenharia de Televisão (SET) sobre os testes de interferência do sinal LTE;

- Testes Laboratoriais e Benchmarking realizado pela Fundação CPqD;

- Testes Laboratoriais realizados no Laboratório CertLab (Ibrace-ICBr);

- Teste laboratorial realizado pela Anatel junto ao Inatel;

- Testes de campo realizado pela Anatel em conjunto com inúmeras instituições dos setores de radiodifusão e de telecomunicações;

- Testes de convivência, elaborado pelo Centro de Estudos em Telecomunicações, da Pontifícia Universidade Católica do Rio de Janeiro.

Determinar as condições em que a convivência entre todos os sistemas possa ocorrer favoravelmente ainda é essencial. Portanto, desenvolver metodologias que subsidiem a compreensão dos fenômenos interferentes deve repercutir na estimativa de interferências e na identificação de dispositivos aptos à mitigação dos mesmos.

Nesse artigo é apresentada uma metodologia de cálculo de MCL, com o propósito de estimar o afastamento mínimo entre sistemas de Televisão digital (TVD), de modo a atender a uma Relação de Proteção (PR) preestabelecida para receptores de $\mathrm{TV}$, frente aos transmissores do SMP que operem em tecnologia Long Term Evolution (LTE).

Este artigo está estruturado da seguinte forma: A Seção II apresenta o desenvolvimento do método de cálculo. Na Seção III são desenvolvidas as funções matemáticas com as quais se torna possível calcular o afastamento necessário entre os sistemas em avaliação. Na Seção IV é exercitada a aplicação do método proposto. $\mathrm{Na}$ Seção $\mathrm{V}$ se avalia um possível desdobramento do método, com possibilidade de estimar o número de filtros necessários para a mitigação da interferência

sinal digital de TV aberta em todo o Brasil - EAD. Os autores são consultores/pesquisadores da Fundação $\mathrm{CPqD}$, vinculados à Diretoria de redes de Comunicações.[manhaes@cpqd.com.br, trindade@cpqd.com.br] 
do LTE em receptores de TVD. Por fim, na Seção VI apresentam-se conclusões decorrentes da elaboração do método, de sua aplicação e possíveis desdobramentos.

\section{Desenvolvimento MetodolóGico}

Segundo o relatório 101 do European Radiocommunications Committee (ERC Report 101) [4], o cálculo de MCL determina o isolamento (em decibel - $\mathrm{dB}$ ) requerido entre um sistema interferente e um sistema vítima, a fim de assegurar uma perda mínima de acoplamento para que não ocorram interferências.

O método de cálculo de MCL é fundamentado em uma análise de pior caso, decorrente da determinação crítica de parâmetros sistêmicos para a transmissão LTE e recepção TVD; desempenho de limiar de sensibilidade do receptor de TVD; visada desobstruída entre antenas de transmissão e de recepção e, por fim, um modelo de propagação.

A partir da função matemática definida pela ERC Report 101 [4] para o cálculo do MCL, pode-se definir a perda necessária ao sinal interferente de modo a se obter o isolamento entre elementos dos sistemas distintos:

- Transmissor interferente LTE e

- Receptor vítima TVD.

Para a determinação do MCL tornam-se implícitas as considerações:

a. Emissões indesejáveis do sinal interferente (ACLR do inglês Adjacent Channel Leakage Ratio) que se sobrepõem à faixa de recepção do receptor vítima;

b. Seletividade do receptor vítima (ACS do inglês Adjacent Channel Selectivity).

A perda necessária ao isolamento é avaliada sob um modelo de propagação, com o qual se define o afastamento mínimo entre os elementos, conforme ERC Report 101 [3].

O propósito do método se torna explicito a partir da determinação do afastamento entre os dois sistemas, com o que é possível definir áreas de exclusão ao redor dos transmissores LTE e avaliar a possibilidade de convivência operacional. Da determinação da área de exclusão torna-se possível avaliar a necessidade de uma ação de mitigação, por exemplo, conforme previsto na Resolução $n^{\circ} 640$, que sugere a adoção de filtros à frente dos receptores de TVD.

A metodologia é composta de 5 etapas, cuja sequência lógica é representada a seguir:

1. Parâmetros críticos do transmissor interferente: são determinados de modo a maximizar as potências emitidas, a largura de ocupação espectral, os efeitos intermitentes (emissão impulsiva ou burst) menores afastamentos espectrais (banda de guarda) e número de portadoras no sistema interferente;

2. Parâmetros críticos do receptor vítima: são determinados pela sensibilidade sistêmica, menor robustez na hierarquia de modulação, forma de recepção por antena interna ou externa, canalização crítica por batimento de frequências, adjacência à faixa espectral interferente, co-atribuição espectral (mesma subfaixa do espectro);

3. Condição mínima não interferente: é determinada pela avaliação da recepção. No caso da TVD, em geral, utiliza-se o conceito de TOV - Threshold of Visibility - Limiar de Visibilidade no qual se busca identificar artefatos não desejados na imagem. Esta condição pode ser estabelecida com base em uma PR determinada em um experimento prático;

4. Minimum Coupling Loss - MCL: definido isolamento em $\mathrm{dB}$, com o qual se estabelece a mínima perda (atenuação) do sinal interferente, para que não produza artefatos interferentes na imagem do receptor vítima.

5. Afastamento mínimo: é a distância mínima entre o receptor de TVD instalado na residência e a antena de transmissão do SMP, atendendo a PR preestabelecida para receptores de TV.

\section{FUnÇÕES MATEMÁTICAS DO MÉTODO}

O cálculo do MCL foi tratado amplamente no ERC Report 101 [4] que objetivou um método unificado para determinar a separação mínima, em frequência, entre dois sistemas operando em faixas adjacentes. A Equação 1, para MCL, definindo o isolamento para emissões não desejáveis é:

$$
\begin{gathered}
I s_{\text {lim }}=P_{I N T}+d B_{B W}+M C_{I N T}+G_{V I C T}+G_{I N T}-\left(S_{V I C T}-C / I_{V I C T}\right)+ \\
f\left(d B c_{I N T}, P_{I N T}\right)
\end{gathered}
$$

Onde:

$I s_{\text {lim }}=$ Isolamento no limiar de recepção da vítima $(\mathrm{dB})$

$P_{I N T}=$ Potência máxima de transmissão do interferente $(\mathrm{dBm})$

$d B_{B W}=$ Fator de conversão de largura de banda entre

interferente e vítima $(\mathrm{dB})$

$M C_{I N T}=$ Margem multiportadora para interferente com mais de uma portadora $(\mathrm{dB})$

$G_{V I C T}=$ Ganho da antena vítima $(\mathrm{dBi})$, subtraindo-se a perda do cabo $(\mathrm{dB})$

GINT $=$ Ganho da antena interferente $(\mathrm{dBi})$, subtraindo-se a perda do cabo $(\mathrm{dB})$

$S_{\text {VICT }}=$ Nível de sensibilidade da vítima $(\mathrm{dBm})$

$C / I_{V I C T}=$ Relação de proteção sistêmica da vítima $(\mathrm{dB})$

$F\left(P_{I N T} / d B c_{I N T,)}=\right.$ Função que define a potência do ruído de banda larga e offset a ser considerado em relação à potência da portadora do interferente $(\mathrm{dB})$

Com uma reorganização dos termos da Equação 1, podem-se identificar aqueles que representam fenômenos interferentes específicos, destacados na Figura 1: 


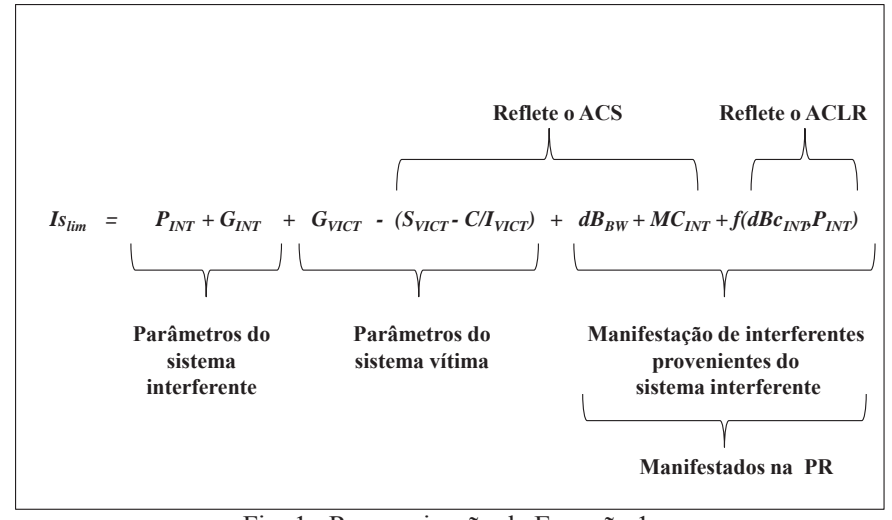

Fig. 1. Reorganização da Equação 1

A partir da reorganização da Equação 1 é possível correlacionar termos aos conceitos ACS e ACLR.

Seguindo a definição da Anatel [5] o "ACS é uma medida de desempenho do receptor relacionada à sua capacidade de receber um sinal em seu canal consignado, dada a presença de outro sinal em um canal adjacente".

O ACS define a capacidade do receptor de receber a energia do canal desejado e de rejeitar interferências provenientes de frequências adjacentes, ou seja, uma expressão intrínseca à seletividade. O valor de ACS é calculado pela Equação 2, conforme o Anexo 2 da Recomendação ITU-R 1368-10 [6]:

$$
A C S=-10 \log \left(10^{-(P R o-P R / 10)}-10^{-(A C L R / 10)}\right)
$$

Onde:

ACS $=$ Seletividade de Canal Adjacente

$P R 0=$ Relação de Proteção de Co-canal

$P R=$ Relação de Proteção

$A C L R=$ Relação de vazamento de Canal Adjacente

O ACLR, que também está associado ao ACS, conforme Anatel [5], "é uma medida de desempenho de um transmissor relacionada à capacidade de supressão de energia no canal adjacente. O ACLR é definido como a razão, em dB, entre a potência média do sinal gerado integrada na sua faixa designada, e a potência média de emissões no canal adjacente."

Da etapa 3 da lógica do método, assumindo que avaliações práticas repercutem em uma determinada $\mathrm{PR}$ ao sistema vítima, em atendimento aos requisitos de relação C/I (Carrier to interference) e sensibilidade de recepção, admite-se que a manifestação dos interferentes já está neutralizada a partir do atendimento ao valor de PR mensurado.

Admitindo-se a manifestação do desempenho de ACS e de ACLR na medida de PR, a Equação 1 pode ser reescrita conforme Equação 3, consolidando a etapa 4:

$$
M C L=I s_{l i m}=P_{I N T}+G_{I N T}+G_{V I C T}-\left(S_{V I C T}+3 d B\right)-P R-D_{a n t}
$$

$I s_{\text {lim }}=$ Isolamento no limiar de recepção da vitima $(\mathrm{dB})$

$P_{I N T}=$ Potência máxima de transmissão do interferente $(\mathrm{dBm})$

$G_{I N T}=$ Ganho da antena interferente (dBi), subtraindo-se a

perda do cabo $(\mathrm{dB})$

$G_{V I C T}=$ Ganho da antena vítima $(\mathrm{dBi})$, subtraindo-se a perda do cabo (dB)

$S_{\text {VICT }}=$ Nível de sensibilidade da vítima $(\mathrm{dBm})$

$P R=$ Relação de Proteção

$D_{a n t}=$ Discriminação de polarização

Na Equação 3 é inserida uma margem de segurança de $3 \mathrm{~dB}$, a fim de atender ao critério de operar acima da sensibilidade de referência.

O termo $\mathrm{D}_{\text {ant }}$ é adicionado para considerar a discriminação de polarização no acoplamento do sinal com a antena de recepção do sistema vítima, pois a frente de onda é emitida em $45^{\circ} \mathrm{em}$ relação ao plano horizontal da antena de recepção.

Na Figura 2 há uma representação gráfica dos níveis relativos aos sistemas, relevando-se as diferenças entre máximos interferentes do LTE, decorrentes de Uplink e de Downlink, em relação ao nível de recepção da TVD, e que resultam no valor de isolamento (MCL).

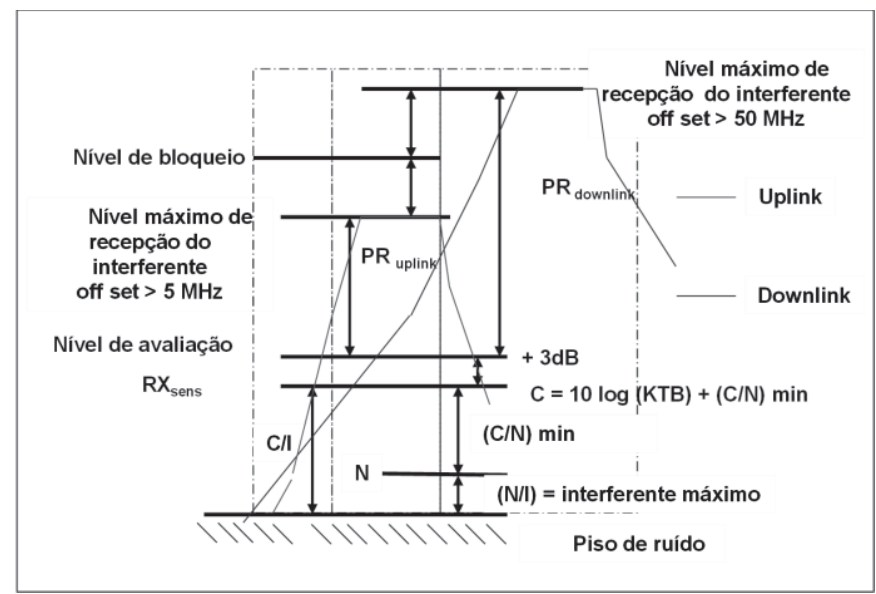

Fig. 2. Representação gráfica do Isolamento para anular interferências de emissões indesejáveis.

A etapa 5 da lógica do método é caracterizada pela Equação 4, derivada da perda de espaço livre, para calcular o afastamento entre as antenas dos sistemas SMP e TVD residencial:

$$
A=\left(10^{(\operatorname{Islim}-32,5-20 \log F) / 20)}\right) \times 1000
$$

Onde:

$A=$ Afastamento

$I s_{\text {lim }}=$ dado pela Equação 3

$F=$ frequência centra da faixa do LTE

A partir da aplicação desta etapa é possível identificar se há necessidade de instalar filtros junto aos receptores residenciais de TV.

\section{APLICAÇÃO DA METODOLOGIA}

Nesta seção é apresentado um exemplo de aplicação do

Onde: 
método proposto. $\mathrm{O}$ objetivo escolhido é estimar o número de filtros necessários para mitigar interferências em receptores de TV Digital, quando instalados nas proximidades de elementos transmissores do LTE. Por finalidade didática, segue-se a aplicação das etapas da metodologia:

\section{Etapa 1: Sistema interferente LTE}

Identificação dos parâmetros do LTE, particularizados para o Uplink e para o Downlink, conforme Tabela I:

TABELA I

PARÂMETROS DO SISTEMA LTE

\begin{tabular}{|c|l|c|c|}
\hline \multicolumn{2}{|c|}{ Parâme tro LTE } & Valor & Unidade \\
\hline \multirow{4}{*}{} & Potência do transmissor LTE & 46,00 & $\mathrm{dBm}$ \\
\cline { 2 - 4 } & Ganho Antena TX LTE & 14,00 & $\mathrm{dBd}$ \\
\cline { 2 - 4 } & Ganho do dipolo/isotrópica & 2,15 & $\mathrm{dBi}$ \\
\cline { 2 - 4 } & Perdas (cabo e conectores) & 0,00 & $\mathrm{~dB}$ \\
\cline { 2 - 4 } & Potência Eirp do transmissor LTE & 62,15 & $\mathrm{dBm}$ \\
\cline { 2 - 4 } & Altura da antena LTE & 30 & $\mathrm{~m}$ \\
\cline { 2 - 4 } & Blocos 2 e 3 & 763 a 773 & $\mathrm{MHZ}$ \\
\hline
\end{tabular}

\section{Etapa 2: Receptor vítima}

Determina-se limiar de recepção normativo, conforme ABNT 15604 [7], ganho de antena e altura de instalação da mesma, conforme valores sugeridos em trabalho de planejamento de Canais, CPqD [8]. Neste exercício é avaliada a recepção com antena externa. Os parâmetros de transmissão da TVD são definidos de forma a se obter o desempenho em situação de menor robustez sistêmica, conforme previsto na ABNT 15601 [9]. De fato, tais parâmetros de configuração de transmissão foram pertinentes na obtenção da PR e, portanto, devem ser registrados para a compreensão plena do resultado obtido. As emissoras de TVD têm generalizado transmissões em configuração correlata, conforme Tabela II

TABELA II

PARÂMETROS DO SISTEMA TVD

\begin{tabular}{|c|c|c|c|}
\hline \multicolumn{2}{|r|}{ Parâme tro TV Digital } & Valor & Unidade \\
\hline \multirow{7}{*}{ 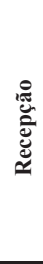 } & Limiar de Rx TV & -77 & $\mathrm{dBm}$ \\
\hline & Altura da antena RX TV & 10 & $\mathrm{~m}$ \\
\hline & Ganho da Antena RX TV & 8 & $\mathrm{dBd}$ \\
\hline & Ganho do dipolo/isotrópica & 2,15 & $\mathrm{dBi}$ \\
\hline & Correção acima do limiar de recepção & 3 & $\mathrm{~dB}$ \\
\hline & Discriminação polarização & 3 & $\mathrm{~dB}$ \\
\hline & Perda na linha $(15 \mathrm{~m})$ & 3 & $\mathrm{~dB}$ \\
\hline \multirow{5}{*}{ 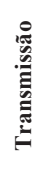 } & Modulação & 64 & QAM \\
\hline & FEC & $3 / 4$ & $\mathrm{n} / \mathrm{a}$ \\
\hline & Intervalo de Guarda & $1 / 16$ & $\mathrm{n} / \mathrm{a}$ \\
\hline & Canal & 51 & $\mathrm{n} / \mathrm{a}$ \\
\hline & Banda de guarda com os blocs LTE & 15 & $\mathrm{MHz}$ \\
\hline
\end{tabular}

OBS: $\mathrm{n} / \mathrm{a}$ - unidade não aplicável
Sendo necessário eleger resultados de PR, considera-se que a consistência da fonte é muito importante. Tomam-se valores determinados nos testes desenvolvidos em laboratório pela Anatel [5], conforme Tabela III.

TABELA III

VALORES DE PR OBTIDOS EM TESTES DA ANATEL

\begin{tabular}{|c|c|c|c|c|c|c|}
\hline Tecnologia & Link & RX & Blocos & BW & Troughput & PR (dB) \\
\hline \multirow{5}{*}{ 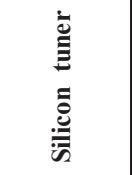 } & \multirow{5}{*}{ 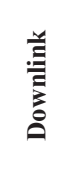 } & 2 & \multirow{5}{*}{$\begin{array}{l}m \\
+ \\
N\end{array}$} & \multirow{5}{*}{$\sum_{0}^{N}$} & idle & 58 \\
\hline & & 3 & & & idle & 61 \\
\hline & & 1 & & & idle & 53 \\
\hline & & 2 & & & $100 \%$ & 63 \\
\hline & & 3 & & & $100 \%$ & 61 \\
\hline
\end{tabular}

Estes resultados decorreram de condições de convivência entre os sistemas TVD e LTE, avaliados sob o pior caso. Estão coerentes com o método aqui proposto, exatamente, adotando os mesmos parâmetros sistêmicos que serão explicitados no passo seguinte.

Das informações colhidas do relatório Anatel [5] adiciona-se a variação de desempenho dos receptores. Esta variável é relevante para compreender que no legado de receptores de televisão, em uso pela população, haverá aqueles com maior ou menor suscetibilidade para evidenciar interferências. Portanto, do pior caso decorrente das condições de convivência, ainda se deve utilizar os limites superior e inferior do desempenho dos receptores. Para efeito deste exercício, serão tomados os seguintes valores:

a) Pior caso RX 2, troughput de $100 \%, P R=63 \mathrm{~dB}$

b) Melhor caso RX 1, troughput em idle mode, $P R=53$ $\mathrm{dB}$

\section{Etapa 4: Minimum Coupling Loss - MCL}

Com base na Equação 3, bem como nos parâmetros definidos nos passos anteriores, torna-se possível determinar o MCL, resultando em:

- $\quad$ Pior caso MCL: 87,30 dB

- $\quad$ Melhor caso MCL; 77,30 dB

\section{Etapa 5: Afastamento mínimo}

Para o cálculo do afastamento mínimo é necessário considerar a posição relativa das antenas de transmissão e de recepção.

Objetivando avaliação mais crítica, determina-se o alinhamento entre os sistemas, conforme a Figura 3 Destaca-se que foram desconsideradas as discriminações de ganho decorrentes de apontamento e de elevação das antenas envolvidas. Desta forma é assegurada a maximização de acoplamento entre os sistemas irradiantes.

Etapa 3: Condição mínima não interferente 


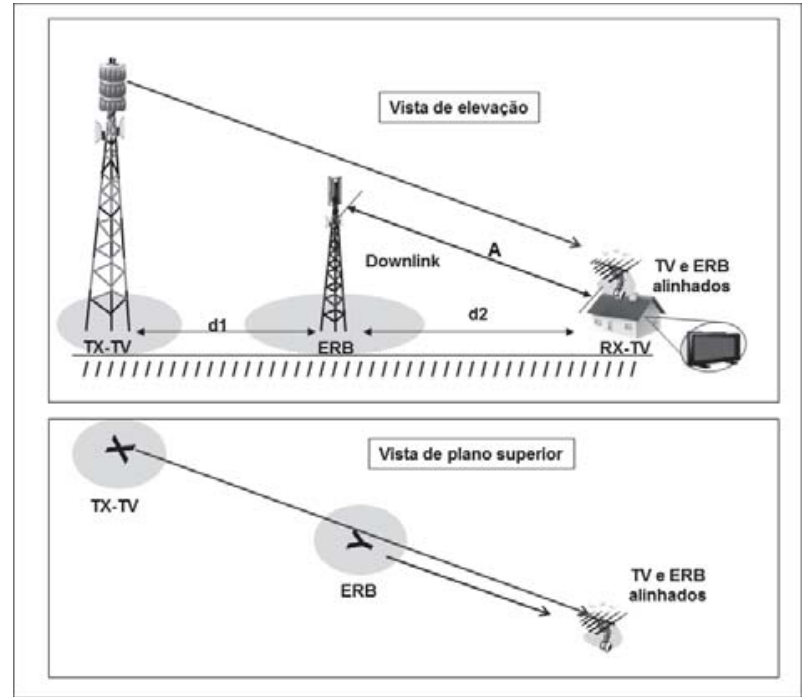

Fig. 3. Posição relativa dos sistemas TVD e LTE.

Admitindo-se visada entre as antenas das Estações Rádio Base (ERB) e de RX TV na residência e ausência de efeitos de discriminação no acoplamento, é utilizada a perda de espaço livre, conforme Equação 4, para determinar o afastamento mínimo.

Como há diferença de alturas das antenas, Figura 3, o Afastamento (A) é corrigido pela função trigonométrica, conforme Equação 5:

$$
\text { Afst }=\left(A^{2}-(H l t e-H t v)^{2}\right)^{0,5}
$$

Onde:

Afst $=$ Afastamento corrigido (distância d2 na Figura 3)

Hlte $=$ Altura da antena do LTE, considerando a cota da base da antena

$H t v=$ Altura da antena da TV, considerando a cota da base da antena

Considerando a PR para dois desempenhos de receptores, são obtidos os seguintes afastamentos mínimos indicados na Tabela IV:

TABELA IV

VALORES DE MCL

\begin{tabular}{|c|l|c|c|}
\hline \multicolumn{2}{|c|}{ Parâme tro LTE } & Valor & Unidade \\
\hline \multirow{3}{*}{$\approx$} & Relação de proteção downlink (PR) & $\mathbf{5 3}$ & $\mathrm{dB}$ \\
\cline { 2 - 4 } & Isolamento Islim (MCL) & $\mathbf{8 7 , 3 0}$ & $\mathrm{dB}$ \\
\cline { 2 - 4 } & Frequência central do canal LTE & 768 & $\mathrm{MHz}$ \\
\cline { 2 - 4 } & Afastamento & 716 & $\mathrm{~m}$ \\
\cline { 2 - 4 } & Afastamento horizontal & $\mathbf{7 1 5}$ & $\mathrm{m}$ \\
\hline \multirow{3}{*}{} & Relação de proteção downlink (PR) & $\mathbf{6 3}$ & $\mathrm{dB}$ \\
\cline { 2 - 4 } & Isolamento Islim (MCL) & $\mathbf{7 7 , 3 0}$ & $\mathrm{dB}$ \\
\cline { 2 - 4 } & Frequência central do canal LTE & 768 & $\mathrm{MHz}$ \\
\cline { 2 - 4 } & Afastamento & 226 & $\mathrm{~m}$ \\
\cline { 2 - 4 } & Afastamento horizontal & $\mathbf{2 2 5}$ & $\mathrm{m}$ \\
\hline
\end{tabular}

Diante das variáveis de pior caso utilizadas como entrada nos cálculos, considera-se que, para a diversidade de receptores de $\mathrm{TV}$, o afastamento mínimo entre uma ERB operando em 700
MHz e um receptor de TV Digital estará situado entre 225 e 715 metros.

\section{DESDOBRAMENTO DA METODOLOGIA}

Chegar ao valor de afastamento é um resultado importante. Entretanto, a finalidade de uso deste resultado ainda pode ser mais significativa: estimar o número de filtros necessários para a mitigação de interferências em receptores de TVD que estejam próximos de ERB do sistema LTE.

Tomam-se as seguintes premissas:

1. Densidade de antenas receptoras $\left(D_{\text {arx }}\right)$ para um cenário urbano residencial de $4,44 \times 10^{-3}$ antenas por $\mathrm{m}^{2}$, ou seja, uma antena de recepção de TVD a cada $225 \mathrm{~m}^{2}$. Essa densidade corresponde ao número de residências distribuídas em uma área urbana de bairros populares, com edificações de um nível.

2. A interferência será efetiva em apenas $120^{\circ}$ no entorno da ERB.

A estimativa do número de antenas é dada pela Equação 6:

$$
\text { \# Filtros }=(1 / \text { Darx }) \cdot(\pi(A f s t 2) / 3)
$$

TABELA V

NÚMERO DE FILTROS

\begin{tabular}{|c|c|c|c|}
\hline Receptor & Rx2 & Rx1 & Unidade \\
\hline Afastamento & 225 & 715 & $\mathrm{~m}$ \\
\hline Área de interferência da ERB & 159044 & 1606064 & $\mathrm{~m} 2$ \\
\hline Área critica 1/3 & 53015 & 535355 & $\mathrm{~m} 2$ \\
\hline \# de filtros & 236 & 2379 & $\mathrm{p} / \mathrm{ERB}$ \\
\hline
\end{tabular}

\section{CONCLUSÃO}

Observando os desenvolvimentos do método e do caso de aplicação, considera-se que sua proposição é favorável para a estimativa ampla do número de filtros necessários à mitigação de interferências provenientes do sistema LTE sobre a recepção de TV.

Os dados práticos das relações de proteção para receptores de TVD já permitem uma extrapolação de números que, todavia, carecem de um desenvolvimento mais elaborado para determinar a distribuição filtros à população. Ou seja, ainda é necessário desenvolver um trabalho que estime a distribuição, e o desempenho correlato dos receptores de TVD nos lares.

Outro ponto relevante é que, até o momento, não há definição de PR para receptores de TV analógica em convivência com o sistema LTE. Entretanto, a partir desta definição, desde que os parâmetros relativos sejam considerados, torna-se factível utilizar o método aqui apresentado para estimar o afastamento mínimo e, com este, o número de receptores de TV analógica sujeitos à interferência. 
Com o método foi possível estimar o número de filtros a serem distribuídos para as residências no entorno de uma ERB. Todavia, por decorrer de exercício de pior caso, admite-se que uma melhor disponibilidade do sinal da TV será significativa para neutralizar efeitos interferentes. Com base na Equação 3, sugere-se avaliar o efeito da redução do afastamento mínimo com o incremento do sinal recebido de TV.

Cabe destacar que o cálculo do afastamento apresentado define uma área, em situação de pior caso da interferência do LTE sobre a recepção da TVD. Para obter a avaliação de interferência da TVD sobre o sistema LTE, o método pode ser aplicado, modificando-se os parâmetros do sistema vítima, nos casos de recepção da ERB e do terminal móvel LTE, e do sistema interferente para aqueles da TVD.

Neste artigo foi apresentada uma estimativa da interferência decorrente do Downlink LTE e, também, seria importante avaliar aquela decorrente do Uplink LTE, bem como, o efeito na recepção de TV com uso de antena interna. Porém, considera-se que empregando medidas de mitigação, tais como uso de filtros no receptor, redução de potência da transmissão interferente ou, por fim, ações que elevem o nível de recepção do sinal desejado no receptor vítima, a convivência entre os sistemas torna-se favorecida.

Finalmente, considerando o resultado do switch off, não foi avaliada a convivência co-canal, prevendo-se que não haverá dois serviços compartilhando a mesma faixa.

\section{REFERÊNCIAS}

[1] Ministério das Comunicações; Portaria $n^{\circ} 481$, de 09 de julho de 2014; consultado em 20/05/2015.

[2] Anatel; Resolução $n^{0}$ 640, de 11 de julho de 2014; consultado em 20/05/2015.

[3] Anatel; Relatório do Teste em Campo sobre a Convivência do LTE na faixa de $700 \mathrm{MHz}$ com ISDB-T Abril, 2014.

[4] European Radiocommunications Committee; Erc Report 101; A Comparison Of The Minimum Coupling Loss Method, Enhanced Minimum Coupling Loss Method, And The Monte-Carlo Simulation; Menton, May 1999.

[5] Anatel; Relatório de Teste Laboratorial de Interferência do LTE na faixa de $700 \mathrm{MHz}$ no ISDB-T; Abril, 2014.

[6] ITU-R; Recommendation ITU-R BT.1368-10 Planning criteria, including protection ratios, for digital terrestrial television services in the VHF/UHF bands; 01/2013.

[7] ABNT; ABNT NBR 15604; Televisão digital terrestre Receptores; Versão corrigida 07.04.2008.

[8] CPqD; Planejamento de Canais de TV Digital; setembro de 2003.

[9] ABNT; ABNT NBR 15601; Televisão digital terrestre Sistema de transmissão; 2007.

Marcus A. R. Manhães nasceu em Guarulhos, SP, em 1960. Recebeu o título de Mestre em Educação pela Universidade de Campinas - UNICAMP, em 2003. De 1993 até a atualidade é pesquisador em sistemas de radiodifusão e de telecomunicações, na Fundação $\mathrm{CPqD}$. Atuou diretamente no grupo de coordenação do processo de definição do sistema de TV Digital para o Brasil, com foco nas soluções de Canal de Interatividade e de Modulação. Desde 2012 produz estudos com base em testes laboratoriais e de campo para a atribuição do dividendo digital, focando o serviço de comunicação. Foi consultor representante do Sinditelebrasil nos testes realizados em Pirenópolis-GO, tornando-se um dos protagonistas na elaboração dos testes e relatórios de Laboratório e de Campo produzidos pela Anatel. Atualmente, perfaz consultoria técnica para a Entidade Administradora de Processo de Redistribuição do sinal digital de TV aberta em todo o Brasil - EAD, atuando no grupo de trabalho GT RX, coordenado pela Anatel, com participação de representantes do setor de radiodifusão pública e comercial.

Marcos B. Trindade nasceu no Rio de Janeiro, RJ, em 1959. Recebeu o título de Mestre em Engenharia Elétrica pela Universidade de Campinas - UNICAMP, em 1992, enfocando Sistemas de Otimização (Operational Research). Trabalhou na Telebahia e Promon/PHT em planejamento de Sistemas de Telecomunicações, abrangendo as disciplinas de tráfego, otimização/dimensionamento, engenharia econômica e confiabilidade de redes. Desde 1992 atua no CPqD como pesquisador/consultor em planejamento de redes de telecomunicações, focando as redes IP multisserviço com QoS, confiabilidade, simulação e otimização de redes NGN, otimização do backhaul LTE (comparando soluções em fibra, cobre, rádio e aluguel EILD) e planejamento de redes de transmissão PDH, SDH e DWDM otimizando a quantidade de comprimentos de onda para atender demandas 100Gbps. Experiência em coordenação de projetos multidisciplinares, de acordo com recomendações do PMI.

Cite this article:

Ribeiro Manhães, M.A. e Baracho Trindade, M.; 2015. Método de cálculo de MCL entre TVD e LTE. SET EXPO PROCEEDINGS. ISSN Print: 2447-0481.ISSN Online: 2447-049X. v.1. doi: 10.18580/setep.2015.1.7 Web-link: http://dx.doi.org/10.18580/setep.2015.1.7 